\title{
An introduction to the Series on Continuing Medical Education
}

Keeping up to date is important for all of us who practice medicine. We strive to keep abreast of important advances in order to base our clinical decisions on the best available evidence. Doing this properly is a daunting task, particularly when faced with the burgeoning medical literature. It has been calculated that to keep up to date in the field of general medicine a physician would need to read 19 journal articles every day 365 days a year. ${ }^{1}$ I am not aware that this figure has been worked out for genitourinary medicine physicians but given the breadth of the specialty and the number of journals in which relevant articles may appear it seems likely that it would involve considerable effort.

Since it is unrealistic to expect practising clinicians to read all the relevant research published in their subject area, what strategies are available to help them keep up to date? Firstly there are guidelines or reviews which have been rigorously developed and validated and which address clinically relevant and important issues. For example The Cochrane Database of Systematic Reviews, a compilation of systematic reviews on all aspects of health care, is published twice a year on computer disc or compact disc. This database is in its infancy but the number of completed reviews increases with each edition. A Cochrane Review Group specifically committed to preparing, maintaining and disseminating systematic reviews on Sexually Transmitted Infections is being formed and so reviews relevant to that area of our practice should find their way onto the database soon. Anyone interested in becoming involved with the Review Group can contact me for further details.

Two bimonthly journals, Evidence-based Medicine and the ACP fournal Club have been developed to help busy clinicians keep abreast of important research developments. These journals screen around 50 journals each month for articles that are relevant to medical practice and are methodologically sound. An informative abstract is published with a commentary from a clinician. The $A C P$ fournal Club includes articles of importance to general physicians while Evidence-based Medicine has a broader remit and includes articles from general practice, obstetrics and gynaecology, surgery, paediatrics and psychiatry. Topics covered in recent editions have included antiretroviral therapy, PCP prophylaxis, mifepristone for induced abortion, famciclovir for herpes zoster and LCR for diagnosis of genital chlamydia.

Unfortunately there is good research evidence showing that traditional continuing medical education (CME) such as attending grand rounds and conferences does little to change how we practice medicine and is ineffective in improving the health outcomes for our patients. ${ }^{2}$ However, a recent systematic review of the effect of different educational strategies in changing physician performance suggests that interactive approaches can be helpful particularly when patient centred. ${ }^{3}$ The newly emerging discipline of evidence based medicine (EBM) uses questions about diagnosis, therapy, prognosis, harm and other health concerns relevant to both patients and physicians to act as the stimulus for searching and critically appraising the scientific literature and then applying the results to clinical practice. Using this problem based approach to answer clinically relevant questions makes reading journal articles about the latest research an extension of clinical practice rather than an arid academic exercise and seems more likely to result in improvements in patient care.

One of the key skills for practising EBM is to be able to critically appraise journal articles in order to separate good studies on which clinical decisions can be based from those which are methodologically unsound. We need to be able to assess both the validity of their recommendations and conclusions as well as their usefulness to our particular patient or practice.

The aim of this new series on Continuing Medical Education will be to include articles on subjects of current interest to the specialty but with a twist. Rather than just presenting a "state of the art" review of a subject, these articles will act as "how to do it" guides for critically appraising papers concerning issues of therapy, diagnosis, prognosis, harm and economic evaluation. I hope this series will be interactive, informative and fun and that readers will learn not only about the subject covered in the article but also how to apply critical appraisal skills when reading other articles.

Department of Sexually Transmitted Diseases,

FRANCES M COWAN University College London Medical School,

Mortimer Market Centre

Off Capper Street,

London WCIE 6AU, UK

1 Davidoff F, Haynes B, Sackett D, Smith R. Evidence based medicine. A new journal to help doctors identify the information they need. $B M \mathcal{F}$ 1995:310:1085-6.

2 Silbey JC, Sackett DL, Neufeld VR, et al. A randomised trial of continuing medical education. $N$ Engl $f$ Med 1982;306:511-5.

3 Davis DA, Thomson MA, Oxman AD, Haynes RB. Changing physicians performance: a systematic review of the effect of educational strategies $\mathfrak{\Im} A M A$ 1995;274:700-5. 